\title{
Analysis of Key Technologies for Industrialized Treatment of Fatty Acid High-Salinity Organic Wastewater
}

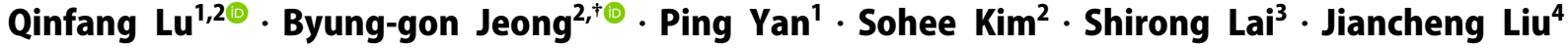 \\ 'School of Chemistry and Environment, Jiujiang University, Jiujiang, China \\ ${ }^{2}$ Department of Environmental Engineering, Kunsan National University, Gunsan, South Korea \\ ${ }^{3}$ Science Environmental Protection Technology Thain Co. Ltd., Jiujiang, China \\ ${ }^{4}$ Lishan Environmental Protection Technology Co. Ltd. COFCO group, Jiujiang, China
}

(Received September 1, 2020; Revised October 19, 2020; Accepted October 27, 2020)

Objectives: Wastewater produced by fatty acid production contains high concentration of organic substances and high concentration of salts (mainly sodium sulfate), causing great pollution to water resources and environment. The pollution prevention and control of this type of wastewater are very necessary. The key to treating this type of wastewater is to remove salts and COD to achieve harmless treatment. This is a problem in wastewater management that has plagued the industry for a long time. This paper proposed a technique suitable for fatty acid high salinity organic wastewater.

Methods: First, the industrial treatment technology of organic wastewater with high salinity was introduced and analyzed. Combined with the principle of industrial wastewater treatment, the process route for the treatment of fatty acid high salinity organic wastewater was analyzed and selected. In addition, the key technology and process for anaerobic desalination and COD removal were analyzed and selected.

Results and Discussion: According to the unique nature of this type of wastewater mainly containing sulphate salts and the feasibility of industrial production, a special technology combination was proposed to treat this wastewater at this stage. Since this wastewater has a $\mathrm{B} / \mathrm{C}$ ratio of 0.4 to 0.45 , it is easier to use biological treatment method. Thus, the conventional treatment method is pretreatment + biological treatment. Biological enhancement and reactor process optimization can be studied for better efficiency.

Conclusions: Considering the high COD and sulphate concentration characteristics of fatty acid high-salinity organic wastewater, high-efficiency anaerobic biochemical treatment is mainly considered. Combined with modern high-efficiency anaerobic suspended sludge granule technology, it was concluded that pretreatment + high efficiency IC anaerobic + secondary biological treatment can achieve industrialized treatment of such wastewater in a targeted, low-cost and reliable way. In the later stage, bio-enhancement of the anaerobic process as well as structural and process optimization of the reactor can be carried out to obtain better technical and economic results in production practice.

Keywords: Fatty Acid, High Salinity Organic Wastewater, Industrialization, Anaerobic Suspended Sludge Granule Technology

\footnotetext{
${ }^{\dagger}$ Corresponding author E-mail: bjeong@kunsan.ac.kr Tel: 063-469-1873 Fax: 063-469-4964

(C) 2020, Korean Society of Environmental Engineers
} 


\section{Introduction}

The production method of fatty acid series products is as follows: the waste materials from vegetable oil and fat processing plants, i.e., the saponins, are acidified by sulfuric acid to obtain crude fatty acids, and then the crude fatty acids are subjected to continuous medium pressure hydrolysis and continuous high vacuum distillation to produce high-quality refined fatty acids, stearic acid and plant pitch. Fatty acid series products are currently the most widely used oleochemical products in the world and are very important industrial raw materials.

Wastewater from fatty acid production mainly comes from acidification, hydrolysis, rectification and other processes. Due to the acidification process and the characteristics of raw materials, in addition to high-concentration organic substances such as phospholipids and soaps as well as pollutants such as acids and suspended solids (SS), the production wastewater also contains high-concentration salts (mainly sodium sulfate). The concentrations of pollutants in the wastewater are as follows: the concentration of animal oil and vegetable oil is $100 \mathrm{mg} / \mathrm{L}$, the concentration of chemical oxygen demand (COD) is $30,000 \sim 60,000 \mathrm{mg} / \mathrm{L}$, and the concentration of SS is $1,200 \sim 3,000 \mathrm{mg} / \mathrm{L}$. The $\mathrm{pH}$ value is about 3.0, and the salt content is $3-5 \%$ (mainly sodium sulfate salt). This type of wastewater is called fatty acid high salinity organic wastewater.

Fatty acid high-salinity organic wastewater is mostly discharged intermittently with complex components, unstable $\mathrm{pH}$, and large variations in water quality and quantity, and can easily cause damage to treatment facilities. The wastewater has large discharge volume and a high concentration of organic matter, which causes great pollution to water resources and environment. The high concentration of soluble inorganic salts and difficult-to-degrade toxic organic matter in wastewater can cause damage to soil, surface water and groundwater. Moreover, in the treatment process, high salt content can inhibit the degradation process of microorganisms and affect the growth and metabolism of microorganisms, which significantly reduces the treatment efficiency of the biological treatment system. As a result, the effluent cannot achieve the desired quality. Therefore, the pollution prevention and control of such wastewater is very necessary. How to treat this type of wastewater with harmless treatment to remove salt and COD is the key to wastewater treatment. This is also a wastewater management challenge that has plagued the industry for a long time.

\section{Principles of industrial wastewater treatment}

In view of the source and composition properties of industrial wastewater, the water quality requirements and objectives to be achieved by wastewater treatment have been clarified. As an auxiliary to industrial production, the selection of environmental protection treatment technology and facilities should not only be technologically advanced, reliable, and meet the national emission standards, but also be economical. That is, the investment should be economically efficient, and the operating cost should be low. Meanwhile, it is also important to consider the loss of consumables and the replacement of spare parts. For example, membrane separation equipment must consider the comprehensive factors of the membrane life cycle and price. In addition, the relevant supporting conditions of the implementing unit, such as the type and price of public works, land prices, labor costs, etc. must be considered. Maximum benefit can only be achieved through comprehensive consideration. ${ }^{1)}$

\section{Analysis of basic treatment technology route for high-salt and high-COD industrial organic wastewater}

High-salt and high-COD industrial organic wastewater refers to the wastewater containing organic matter of $\rho(\mathrm{COD})>$ $4,000 \mathrm{mg} / \mathrm{L}$, inorganic salt $\left(\mathrm{Na}^{+}, \mathrm{Cl}^{-}, \mathrm{Ca}^{2+}, \mathrm{SO}_{4}{ }^{2-}\right.$, etc. $)>1 \%$ (the salt content is the amount of sodium chloride) and the total dissolved solids (TDS) $>3.5 \%$. According to the characteristics of high salt and high COD in the wastewater, the current common industrial treatment technology routes of salt-containing high COD wastewater mainly include evaporation crystallization process, electrolysis process, membrane separation process, incineration process, biochemical treatment process, etc.

\subsection{Evaporation crystallization process}

In the evaporation crystallization method, heating is used to vaporize part of the water and low-boiling organics in the high-salt wastewater at a relatively high temperature $\left(50 \sim 150^{\circ} \mathrm{C}\right)$. During the evaporation crystallization process, the concentration of salt and high-boiling organics in the remaining sewage gradually increases to reach saturation. 
After the saturation concentration is achieved, the salt precipitates, and the salt and water are separated, thereby avoiding the influence of salinity in most wastewater on the biochemistry of wastewater. This method can remove up to $100 \%$ of the salt in wastewater. This process is suitable for high-salt organic wastewater with a low COD concentration. The organics in the wastewater should be volatile organics or semi-volatile organics. The main evaporation technologies include membrane distillation (MD), multistage flash evaporation (MSF), multi-effect distillation (MED), and mechanical vapor compression evaporation (MVC).

The bottleneck of the evaporation crystallization process is the large energy consumption. In addition, if there are organics with high boiling point that cannot be removed in the evaporation system, the concentration gradually increases, and the evaporated material becomes viscous. It will affect the evaporation effect and even block the heat exchanger. In general, industrial production often regularly discharges the waste. ${ }^{1)}$ Although the amount of discharged waste is small, the high-salt, high-COD nature of the waste liquid further increases the difficulty of subsequent treatment. There is no ideal way to remove the concentrated liquid after the evaporation process. If the cost of hazardous waste disposal cost of hazardous waste disposal is too high, the company basically does not consider this method.

\subsection{Electrolysis process}

High-salt wastewater contains a large number of ions, so the high-salt wastewater has good electrical conductivity, which provides a new idea for the treatment of high-salt wastewater. According to the redox reaction principle of the electrode in the electrolysis process, the substances in the high-salt wastewater undergo corresponding redox at the anode and cathode, which can directly redox the organic substances in the wastewater, thereby reducing COD and realizing the purification of wastewater. If the high-salt wastewater contains a large amount of $\mathrm{NaCl}$ during the electrolysis process, chlorine gas will be generated on the anode. Then, the chlorine gas reacts with water to form chlorate and hypochlorite, which can disinfect and bleach the wastewater.

However, the process cannot effectively remove the salt from the wastewater and the operating cost per ton of water is expensive. Thus, this method is not suitable for large-scale industrial applications.

\subsection{Membrane separation process}

Membrane separation technology uses the pressure or chemical potential difference on both sides of natural or synthetic membranes as the driving force and uses membranes of different pore sizes and different materials to separate, purify and concentrate substances in wastewater under a certain pressure or chemical potential difference. Commonly used membrane separation technologies include nanofiltration (NF) ${ }^{2)}$, ultrafiltration (UF), microfiltration (MF), forward osmosis (FO), reverse osmosis (RO), electrodialysis (ED), etc. The advantages of membrane separation method include no need to add chemicals, high separation efficiency, low energy consumption, strong applicability, and easy control automation. Its disadvantages include expensive equipment and operating costs, as well as easy clogging of membranes during operation. In addition, the membrane separation system is a separation and concentration process. When the wastewater is separated by membrane, one side of the membrane will result in sufficiently treated water, while the other side will get high-salt, high-COD water. The high-salt, high-COD water needs to be further treated by other technologies.

This fatty acid high-salinity wastewater has high oil content and high SS. In actual production and operation, the membrane is a vulnerable part, which can easily be blocked and polluted. ${ }^{3,4)}$ The membrane needs to be periodically replaced. The replacement cost and the overall equipment cost are expensive, which has a great impact on the overall economic benefits of the project. Therefore, the membrane separation method should not be adopted to treat this type of wastewater in industrial projects.

\subsection{Incineration process}

The incineration method is a high-temperature pyrolysis treatment technology. In the incineration method, the organic matter in the wastewater undergoes a violent chemical reaction with the oxygen in the air at a high temperature of $800-1,000^{\circ} \mathrm{C}$ to produce water, $\mathrm{CO}_{2}$ and inorganic ash, and release a large amount of energy. At the high temperature, the organic matter in wastewater is decomposed and transformed into non-polluting small molecules. This treatment technology can simultaneously realize the harmlessness, reduction and resource utilization of waste. Using this treatment technology, the organic matter in high-salt water can be directly removed, and the salt is discharged as a residue, thus the high-salt wastewater can be effectively treated. This method is more 
suitable to treat high-salt organic wastewater with a certain calorific value. It has a relatively low cost and simple process flow. However, due to the high temperature, coking easily occurs, causing corrosion of the furnace, thus reducing the efficiency of wastewater treatment. Moreover, there are high requirements for incineration technology and incinerators.

Incineration process has a large amount of external heating and high operating costs. At the same time, waste gas is generated during incineration, thus waste gas treatment is required. The equipment of incineration process needs special anti-corrosion treatment. In addition, the subsequent treatment of waste gas requires high requirements and the equipment investment is expensive. Therefore, industrial incineration technology is not suitable for this wastewater treatment.

\subsection{Biochemical process}

Biochemical method uses the metabolism of microorganisms to convert organic pollutants in dissolved and colloidal state into harmless substances to achieve purification. Due to its low cost in sewage treatment, this method is preferred and most commonly used in sewage treatment schemes. It is also the most promising method in the treatment of high-salt wastewater. ${ }^{5,6)}$ However, when the organic wastewater with high salinity is post-treated by biochemical methods, the high salinity has a strong inhibitory effect on the growth of microorganisms and reduces the treatment effect. Therefore, in the biological treatment of high-salt organic wastewater, it is necessary to reduce the inhibition and toxicity of high-concentration soluble inorganic salts on microorganisms. ${ }^{5)}$ Specific salt-tolerant strains can be used to form suitable wastewater degrading strains (bacteria) through oriented culture and domestication with high-salt water, thereby reducing COD in wastewater through biochemical methods. This method can be appropriately combined with the existing biochemical treatment equipment in the factory to form a convenient high-salt water treatment process technology.

In mature industrial applications of salt-tolerant bacteria to remove $\mathrm{COD}$, the salt-tolerant bacteria generally contain less than $3 \%$ salt. The selection of salt-tolerant bacteria with higher salt concentration is more difficult and the domestication time is longer. At present, this method basically only exists in experimental research and has not been put into industrial operation practice. ${ }^{1)}$ Such methods require relatively stable salt content in salt-tolerant bacteria. After the bacteria are domesticated in water with a certain salt content, if the water quality is unstable and the salt concentration is too low or too high, the strain is prone to widespread mortality. The water quality of fatty acid high-salinity organic production wastewater changes with the production of acidified oil, and it is extremely difficult to be treated with salt-tolerant bacteria. Therefore, the treatment with salt-tolerant bacteria may not be suitable for industrial application.

\section{Selection of basic process route for treatment of fatty acid high salinity organic wastewater}

\subsection{Selection of process route}

Two issues need to be considered in the treatment of fatty acid high-salinity organic wastewater, i.e., high concentration of organic matter and desalination. As mentioned above, it is difficult to achieve a fundamental solution for the treatment of fatty acid high salinity wastewater using existing conventional methods or process routes. According to the unique nature of this type of wastewater containing mainly sulphate and the feasibility of industrial production, a special combination of technology is proposed to treat this wastewater at this stage.

Since this wastewater has a $\mathrm{B} / \mathrm{C}$ ratio of 0.4 to 0.45 , it is easier to use biochemical treatment. Thus, the conventional treatment method is pretreatment + biochemical treatment.

In terms of pretreatment, the low-cost lime precipitation method should be considered. Based on the slightly soluble characteristics of $\mathrm{CaSO}_{4}, \mathrm{Ca}^{2+}$ reacts with $\mathrm{SO}_{4}{ }^{2-}$ in the wastewater to form a precipitate.

For the biochemical technologies, the aerobic technology can be used for low-concentration sulphate organic wastewater. The aerobic technology with higher oxygen supply efficiency includes aerated biological filter, biological fluidized bed, deep well aeration device and pure oxygen activated sludge. However, aerobic bacteria are not sensitive to sulfate, and aerobic conditions are not conducive to the growth of sulfate-reducing bacteria (SRB), thus the sulfate removal effect is not good. In addition, wastewater contains relatively high concentrations of organic matter. Due to the limited oxygen supply capacity, this type of wastewater needs to be diluted before aerobic treatment, which often causes a large amount of economic costs and energy consumption. In anaerobic treatment technology, the entire aeration process of the aerobic process can be saved, thus greatly reducing the 


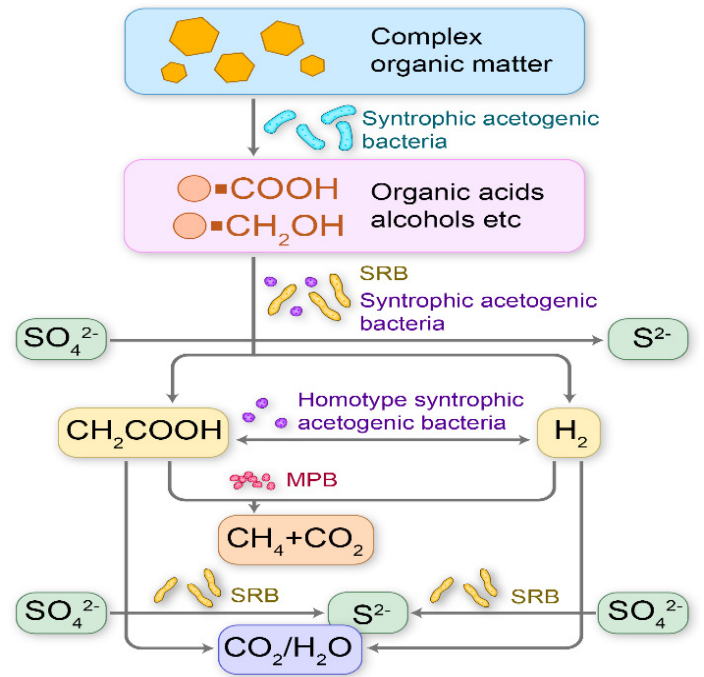

Fig. 1. Anaerobic degradation of organic matters in the presence of sulfate.

cost. In addition, the generated biogas can be used for power generation and combustion. Furthermore, in the presence of sulfate and sufficient carbon source, the anaerobic process can utilize the metabolic conversion of sulfate bacteria, including SRB and sulfur bacteria, to reduce sulfate to sulfide, and then to sulfur monomers via sulfur bacteria. Thus, sulfate is reduced to dissolved sulfide or ammonia sulfide gas. ${ }^{7)}$

The degradation process of the anaerobic digestion system in the presence of sulfate is summarized in Fig. 1. ${ }^{7)}$ On the one hand, SRB can directly use the methanogenic precursors, acetic acid and $\mathrm{H}_{2} / \mathrm{CO}_{2}$ as electron donors to reduce sulfate to sulfide. On the other hand, SRB can also use intermediate products in the fermentation process of organic matter such as propionic acid, butyric acid, and ethanol to reduce sulfate and produce acetic acid and sulfide. In addition, studies have found that SRB can also directly use sugars as electron donors to reduce sulfate. ${ }^{7)}$

Furthermore, the anaerobic process treatment of high-concentration sulfate organic wastewater also has the advantages of reducing nutrient dosage, relatively small sludge output, lowering the pressure of the subsequent sludge disposal process, small anaerobic equipment, small footprint, and low investment.

Therefore, for the biochemical treatment of high COD and sulphate wastewater, high-efficiency anaerobic biochemical treatment is mainly considered, followed by aerobic biochemical treatment with long residence time. The key to this route is the low cost and high reliability of pretreatment + high-efficiency anaerobic biochemical process + secondary biochemical process route. The basic route is shown in Fig. 2.

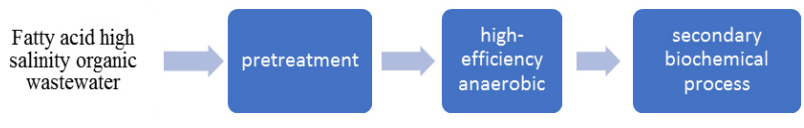

Fig. 2. Technical route of fatty acid high salinity organic wastewater treatment.

\subsection{Key technology and process selection for anaerobic desalination and COD removal}

\subsubsection{Brief introduction of modern high-efficiency anaerobic technology}

As a low-cost biotechnology, anaerobic biochemical treatment technology can stably and efficiently remove pollutants under high organic load, thereby simultaneously achieving the degradation of pollutants and the recovery of resources. It is usually used as a core technology for industrial enterprises with serious environmental problems and insufficient funds. ${ }^{8)}$ At present, anaerobic biochemical technology has been applied in the treatment of a variety of high-concentration organic wastewater, including grease wastewater ${ }^{9)}$, pharmaceutical wastewater ${ }^{10)}$, leachate ${ }^{11)}$ and starch wastewater. ${ }^{12)}$ In addition, anaerobic digestion is also used to recover energy from surplus sludge ${ }^{13)}$ and solid wastes such as domestic garbage and livestock manure. ${ }^{14)}$ The core facility of anaerobic process, i.e., anaerobic reactor, has naturally attracted great interest from scholars around the world.

During anaerobic digestion of high concentrations of organic wastewater containing sulphate, SRB compete with methane-producing bacteria (MPB) for substrates and inhibits MPB. At the same time, the sulfate produced in the reduction reaction by SRB also has a toxic effect on MPB and other anaerobic bacteria, thus affecting the treatment effect of the anaerobic reactor. ${ }^{15-19)}$ For this reason, researchers used a two-phase process to separate the sulfate reduction process from the methane production process to eliminate the impact of SRB on $\mathrm{MPB}^{20)}$, which made the process complicated and expensive. With the in-depth research on SRB and the development of anaerobic reactors, researchers and engineers are increasingly interested in using some modern new high-efficiency anaerobic reactors to treat high-sulfate wastewater. ${ }^{21-31)}$

Modern anaerobic treatment systems depend to a certain extent on the formation of a stable and balanced micro-ecosystem. In a traditional anaerobic reactor, the sludge is distributed in layers. In the lower layer, the sludge concentration is higher, and the structure is denser. At the same time, the liquid phase often contains higher concentrations of metabolites and inert 
Table 1. Main characteristics of EGSB and IC reactors.

\begin{tabular}{|c|c|c|c|c|c|c|c|}
\hline \multirow{3}{*}{$\begin{array}{l}\text { Reactor } \\
\text { type }\end{array}$} & \multirow{3}{*}{ Commonality } & \multicolumn{6}{|c|}{ Peculiarities } \\
\hline & & \multicolumn{2}{|c|}{ Structure size } & \multirow{2}{*}{$\begin{array}{l}\text { Reaction } \\
\text { chamber }\end{array}$} & \multirow{2}{*}{$\begin{array}{l}\text { Flow rate (including } \\
\text { reflux, } m \cdot h^{-1} \text { ) }\end{array}$} & \multirow{2}{*}{$\begin{array}{l}\text { Circulation } \\
\text { mode }\end{array}$} & \multirow{2}{*}{$\begin{array}{c}\text { Power } \\
\text { consumption }\end{array}$} \\
\hline & & Height (m) & Aspect ratio & & & & \\
\hline EGSB & $\begin{array}{l}\text { 1. The third generation of anaerobic } \\
\text { reactor; } \\
\text { 2. Derived from the improvement of } \\
\text { UASB; } \\
-3 \text { Suspended granular sludae reactors: }\end{array}$ & $12 \sim 16$ & $15 \sim 40$ & 1 & $2.5 \sim 12$ & Exterior & High \\
\hline IC & $\begin{array}{l}\text { 4. Reflux ratio } 200-300 ; \\
\text { 5. Small footprint; } \\
\text { 6. Have circulation; } \\
\text { 7. Produce clean energy-biogas }\end{array}$ & $18 \sim 24$ & $4 \sim 8$ & $\begin{array}{l}2 \text { USAB } \\
\text { Series } \\
\text { connection }\end{array}$ & $6 \sim 16$ & Interior & Low \\
\hline
\end{tabular}

substances that are difficult to degrade, which directly restricts the nutrient intake and normal metabolism of organisms. Therefore, the immobilization process of microorganisms through granular sludge is extremely important. The use of sludge granulation technology greatly prolongs the retention time of sludge and creates conditions for sludge reflux. The synergistic effect of microbial flora can keep the concentration of inhibitor at a low level. At the same time, the kinetic parameters of organic matter degradation, diffusion or convective mass transfer are significantly enhanced. ${ }^{32)}$ The good settling performance of granular sludge solves the problem of granular sludge loss under high load conditions and creates the conditions for improving the reactor capacity. Currently, the most reported anaerobic reactors mainly include upflow anaerobic sludge bed reactor (UASB) ${ }^{33-36)}$, anaerobic fluidized bed, anaerobic composite reactor, expanded granular sludge bed reactor (EGSB) ${ }^{32,37-41)}$, internal circulation reactor $(\mathrm{IC})^{42-44)}$, etc.

\subsubsection{Suspended sludge granulation technology}

The high-speed anaerobic reactor designed with suspended particle sludge technology has greatly improved the mass transfer conditions and flow conditions in the reactor. ${ }^{45-47)}$ Thus, the load and treatment efficiency of the reactor are increased, the retention time of the wastewater in the reactor is shortened to a few hours, and the volume of the reactor is greatly reduced. The extension of the SRT in the reactor and the increase of the sludge concentration improve the stability of the anaerobic, which is conducive to the treatment of various complex industrial wastes using anaerobic technology. Generally, in the design of the reactor structure, the methods such as effluent reflux and large height-to-diameter ratio design were adopted to increase the rising speed of the inlet water surface, so that the granular sludge is suspended in the wastewater to realize the fluidization of the granular sludge. ${ }^{48)}$

The suspension growth reactors such as EGSB and IC reactors rely on a high liquid rising flow rate $\mathrm{V}_{\text {up }}$ and a large amount of produced biogas to ensure the granular sludge always in a good suspension state. The granular sludge plays a similar role to the filler, solid support or carrier in the attached growth reactor. However, the microbial carrier in EGSB and IC reactors is granular sludge with self-regulating ability, good settling performance and high biological activity. EGSB and IC reactors make full use of mature biological and engineering technologies such as sludge granulation $^{49}$ ), fluidization, feedback control (reflux), and large height-to-diameter ratio design. Meanwhile, the performance of granular sludge as a microbial polymer is adjusted according to the operating conditions and treatment load of the reactor, which overcomes the disadvantages of the adhesion growth reactor caused by the fillers, such as easy clogging and larger power consumption. Therefore, these two reactors become the typical representatives of the third generation of anaerobic reactors. The comparison of the main characteristics of both reactors is shown in Table 1.

From Table 1, compared with the IC reactor, the height-to-diameter ratio of the EGSB reactor is too large, which is unfavorable in reactor production and construction installation. In addition, the power consumption affects the economy. Therefore, when selecting the key anaerobic reactor, more emphasis was put on the IC reactor. IC anaerobic reactor has advantages of high volumetric load rate, short hydraulic retention time, impact resistance, avoiding solid deposits, low infrastructure investment and small footprint, reduced energy consumption based on the internal circulation through biogas, and good stability of effluent. It represents the highest level of anaerobic reactors in the world today.

Due to the unique structure, the IC reactor also has excellent performance under high load. ${ }^{50)}$ IC reactors can often handle 
loads (OLRs) up to 3-5 times higher than UASBs. ${ }^{15)}$ After decades of development, IC reactors have been widely recognized and applied in the treatment of a variety of high-concentration industrial wastewater. ${ }^{51,52)}$ The companies using IC reactors include Jiangxi Musashi Wild Chemical Co., Ltd. (mainly producing L-lactic acid, food additives), Jiangxi Xinruifeng Chemical Co., Ltd. (gibberellin), Jiangxi Nanchang Jisheng Pharmaceutical Factory (Paishi Granules), etc. The internal circulation IC reactor can be selected as the key technology of high-efficiency anaerobic wastewater.

\subsubsection{Analysis of improvement directions of key technologies}

In actual operation, this technical route still has problems such as low COD treatment efficiency, low processing load of IC tower, and unstable formation of granular sludge. Therefore, an improvement plan is considered for this key technology.

At present, the research hotspots of high-efficiency anaerobic reaction process of high-salt organic wastewater mainly include high-efficiency reactors ${ }^{53-65)}$, bio-enhancement ${ }^{66-73)}$, etc. Bio-enhancement includes application research of new biological carriers $^{66-69)}$, selection of inoculated sludge ${ }^{63,70-73)}$, etc. The examples are shown as follows:

Kok Kwang $\mathrm{Ng}$ et al. ${ }^{66)}$ used a new type of bio-carrier enhanced anaerobic membrane bioreactor (AnBEMR) to treat high-salt pharmaceutical wastewater and operated at an OLR between 8.0 and $36.7 \mathrm{~kg} \mathrm{COD} / \mathrm{m}^{3} \mathrm{~d}$. The experimental results showed that AnBEMR enhanced with a carrier exhibited good processing performance, which was about 5-10\% higher TCOD removal rate and about $15 \%$ higher methane yield than AnMBR without carrier enhancement. In addition, marine sediment was used to replace traditional activated sludge. ${ }^{67)}$ Experiments showed that marine sediment inoculation exhibited much better treatment performance than traditional activated sludge.

Weilong Song et al. ${ }^{68)}$ successfully developed a new carrier-enhanced membrane bioreaction system for the treatment of salty wastewater from saltwater mariculture.

Songwen Tan et al. $^{70)}$ proposed a technology for treating saline wastewater using seawater activated sludge with sea mud as seeds. The typical phenol-resistant microorganisms were separated from the marine activated sludge. After domestication, the marine activated sludge was used to treat high-salinity industrial phenol wastewater. Marine activated sludge can effectively decompose phenol and other organic components, and treat wastewater with the salinity of $5.7 \%$.
The results showed that the removal rates of phenol, COD, and $\mathrm{NH}_{3}-\mathrm{N}$ were $99 \%, 80 \%$, and $68 \%$, respectively.

Jilin Huang et al. ${ }^{71)}$ used estuary sludge in the inoculation. They found that salt-tolerant sludge had significant granulation, which provided an effective method to solve the problem of sludge loss in the salt-containing sewage treatment. The results showed that when the salt content of the wastewater was $3 \%$, the salt-tolerant granular sludge with a particle size of $1,155 \pm 102 \mu \mathrm{m}$ was formed. Due to the increase of OLR, the total amount of extracellular polymeric substance (EPS) was doubled, and protein dominated the EPS $(72.8 \pm 2.0 \%)$.

Manal Ali et al. ${ }^{72)}$ studied the performance of a salt-adapted mixed culture fixed sludge anaerobic reactor (ISABR) in the treatment of salt-containing industrial wastewater.

According to the current situation of anaerobic biological treatment of fatty acid high-salt organic production wastewater, in order to better solve the problems in the wastewater process, the current research hotspots were combined to study the optimal selection of the high-efficiency anaerobic reactors, bio-enhancement, reactor process optimization, etc. In terms of biological enhancement, the carrier enhancement and anaerobic sludge domestication process can be studied. For example, the researches can focus on studying new carriers and investigating whether the new carriers are suitable for enhancing reaction processes, such as IC. Reactor process optimization can be combined with today's hot topic, Computational Fluid Dynamics $\mathrm{CFD}^{74)}$, for structural design and optimization of operating conditions. Moreover, the above studies are important to test the feasibility and reliability of the industrial applications.

\section{Summary}

Through the analysis of treatment technology route for the high-COD and high-salt water, the technical solution of the industrial treatment technology of fatty acid high-salinity organic production wastewater was analyzed. The results showed that pretreatment + high efficiency IC anaerobic + secondary biological treatment can achieve industrialized treatment of such wastewater in a targeted, low-cost and reliable way. In the later stage, bio-enhancement of the anaerobic process as well as structural and process optimization of the reactor can be carried out to obtain better technical and economic results in production practice. 


\section{References}

1. M. Zhou, F. Deng, The industrial technology analysis of PPS high salinity organic wastewater, Synthetic Technology and Application, 33(2), 49-52(2018).

2. M. V. Galiana-Aleixandre, A. Iborra-Clar, A. Bes-Pia, J. A. Mendoza-Roca, B. Cuartas-Uribe, M. I. Iborra-Clar, Nanofiltration for sulfate removal and water reuse of the pickling and tanning processes in a tannery, Desalination, 179(1-3), 307-313(2005)

3. T. J. K. Visser, S. J. Modise, H. M. Krieg, K. Keizer, The removal of acid sulphate pollution by nanofiltration, Desalination, 140(1), 79-86 (2001).

4. A. Rahardianto, J. Gao, C. J. Gabelich, M. D. Williams, Y. Cohen, High recovery membrane desalting of low-salinity brackish water: integration of accelerated precipitation softening with membrane RO, J. Membr. Sci., 289(1-2), 123-137(2007).

5. Y. Zhao, X. Zhuang, S. Ahmad, S. Sung, S. Q. Ni, Biotreatment of high-salinity wastewater: current methods and future directions, World J. Microbiol. Biotechnol., 36, $37(2020)$.

6. O. Lefebvre, R. Moletta, Treatment of organic pollution in industrial saline wastewater: a literature review, Water Res., 40(20), 3671-3682(2006).

7. G. Luo, Treatment of sulfate-rich organic wastewater by internal circulation (IC) anaerobic reactor, Master Dissertation, Nanjing University(2017).

8. Z. Kong, L. Li, Y. Xue, M. Yang, Y.-Y. Li, Challenges and prospects for the anaerobic treatment of chemical-industrial organic wastewater: a review, J. Cleaner Prod., 231, 913-927 (2019).

9. J. Jeganathan, G. Nakhla, A. Bassi, Long-term performance of high-rate anaerobic reactors for the treatment of oily wastewater, Environ. Sci. Technol., 40(20), 6466-6472(2006).

10. Z. Chen, Y. Wang, K. Li, H. Zhou, Effects of increasing organic loading rate on performance and microbial community shift of an up-flow anaerobic sludge blanket reactor treating diluted pharmaceutical wastewater, J. Biosci. Bioeng., 118(3), 284-288(2014).

11. T. Yilmaz, D. Erdirencelebi, A. Berktay, Effect of $\mathrm{COD} / \mathrm{SO}_{4}{ }^{2-}$ ratio on anaerobic treatment of landfill leachate during the start-up period, Environ. Technol., 33(3), 313-320(2012).

12. X. Lu, G. Zhen, A. L. Estrada, M. Chen, J. Ni, T. Hojo, K. Kubota, Y.-Y. Li, Operation performance and granule characterization of upflow anaerobic sludge blanket (UASB) reactor treating wastewater with starch as the sole carbon source, Bioresour. Technol., 180, 264-273(2015).

13. J. Wu, J. B. Zhang, Y. Jiang, Z. P. Cao, S. Poncin, H. Z. $\mathrm{Li}$, Impacts of hydrodynamic conditions on sludge digestion in internal circulation anaerobic digester, Process Biochem., 47(11), 1627-1632(2012).

14. I. M. Nasir, T. I. M. Ghazi, R. Omar, Production of biogas from solid organic wastes through anaerobic digestion: a review, Appl. Microbiol. Biotechnol., 95(2), 321-329(2012).

15. Y. Chen, J. J. Cheng, K. S. Creamer, Inhibition of anaerobic digestion process: a review, Bioresour. Technol., 99(10), 4044-4064(2008).

16. P. N. L. Lens, A. Visser, A. J. H. Janssen, L. W. Hulshoff Pol, G. Lettinga, Biotechnological treatment of sulfate-rich wastewaters, Crit. Rev. Environ. Sci. Technol., 28(1), 41-88(1998).

17. Z. Isa, S. Grusenmeyer, W. Verstraete, Sulfate reduction relative to methane production in high-rate anaerobic digestion: technical aspects, Appl. Environ. Microbiol., 51(3), 572-579(1986).

18. E. Choi, J. M. Rim, Competition and inhibition of sulfate reducers and methane producers in anaerobic treatment, Water Sci. Technol., 23(7-9), 1259-1264(1991).

19. Z. Jing, Y. Hu, Q. Niu, Y. Liu, Y.-Y. Li, X. C. Wang, UASB performance and electron competition between 61methane-producing archaea and sulfate-reducing bacteria in treating sulfate-rich wastewater containing ethanol and acetate, Bioresour. Technol., 137, 349-357(2013).

20. C. H. Wei, W. X. Wang, Z. Y. Deng, Characteristics of high-sulfate wastewater treatment by two-phase anaerobic digestion process with Jet loop anaerobic fluidized bed, J. Environ. Sci., 19(3), 264-270(2007).

21. E. Sarner, Removal of sulphate and sulphite in an anarobic trickling (ANTRIC) filter, Water Sci. Technol., 22(1-2), 395-404(1990).

22. J. Dries, A. D. Smul, L. Goethals, H. Grootaerd, W. Verstraete, High rate biological treatment of sulfate-rich wastewater in an acetate-fed EGSB reactor, Biodegradation, 9(2), 103-111(1998)

23. T. Yamaguchi, H. Harada, T. Hisano, S. Yamazaki, I.-C. Tseng, Process behavior of UASB reactor treating a wastewater containing high strength sulfate, Water Res., 33(14), 3182-3190(1999).

24. A. Sarti, M. Zaiat, Anaerobic treatment of sulfate-rich wastewater in an anaerobic sequential batch reactor (AnSBR) using butanol as the carbon source, J. Environ. Manage., 92(6), 1537-1541(2011).

25. J. Li, J. Wang, Z. Luan, Z. Ji, L. Yu, Biological sulfate removal from acrylic fiber manufacturing wastewater using a two-stage UASB, J. Environ. Sci., 24(2), 343-350(2012).

26. T. P. Delforno, A. G. L. Moura, D. Y. Okada, M. B. A. Varesche, Effect of biomass adaptation to the degradation of anionic surfactants in laundry wastewater using EGSB reactors, Bioresour. Technol., 154, 114-121(2014).

27. G. Luo, J. Li, Y. Li, Z. Wang, W. T. Li, A. M. Li, Performance behaviors and microbial community of circulation anaerobic treating wastewater with high organic loading rate: role of external hydraulic circulation, Bioresour. Technol., 222, 470-477(2016).

28. X. Chen, Y. Wang, Z. Wang, S. Liu, Efficient treatment of traditional Chinese pharmaceutical wastewater using a pilot-scale spiral symmetry stream anaerobic bioreactor compared with internal circulation reactor, Chemosphere, 228, 437-443(2019)

29. J. D. Muñoz Sierra, M. J. Oosterkamp, W. Wang, H. Spanjers, J. B. van Lier, Comparative performance of upflow anaerobic sludge blanket reactor and anaerobic membrane bioreactor 
treating phenolic wastewater: overcoming high salinity, Chem. Eng. J., 366, 480-490(2019).

30. S. C. Bhuyan, A. K. Swain, A. Sahoo, S. K. Bhuyan, Nutrient (sulphate) removal from wastewater in inverse fluidized bed biofilm reactor, Mater. Today: Proc., (2020).

31. A. Foglia, C. Akyol, N. Frison, E. Katsou, A. L. Eusebi, F. Fatone, Long-term operation of a pilot-scale anaerobic membrane bioreactor (AnMBR) treating high salinity low loaded municipal wastewater in real environment, Sep. Purif. Technol., 236, 116279(2020).

32. G. Lettinga, J. Field, J. Van Lier, G. Zeeman, L. W. Huishoff Pol, Advanced anaerobic wastewater treatment in the near future, Water Sci. Technol., 35(10), 5-12(1997).

33. G. Lettinga, A. F. M. van Velsen, S. W. Hobma, W. de Zeeuw, A. Klapwijk, Use of the upflow sludge blanket (USB) reactor concept for biological wastewater treatment, especially for anaerobic treatment, Biotechnol. Bioeng., 22(4), 699-734(1980).

34. M. T. Kato, J. A. Field, R. Kerebezerm, G. Lettinga, Treatment of low strength soluble wastewater in UASB reactors, J. Ferment. Bioeng., 77(6), 679-686(1994).

35. S. Uemura, H. Harada, Treatment of sewage by a UASB reactor under moderate to low temperature conditions, Bioresour. Technol., 72(3), 275-282(2000).

36. R. Z. Gaur, A. A. Khan, B. Lew, V. Diamantis, A. A. Kazmi, Performance of full-scale UASB reactors treating low or medium strength municipal wastewater, Environ. Processes, 4(1), 137-146(2017).

37. M. T. Kato, J. A. Field, G. Lettinga, The anaerobic treatment of low strength wastewater in UASB and EGSB reactors, Water Sci. Technol., 36(6-7), 375-382(1997).

38. L. A. Nuneu, B. Martfnez, Anaerobic treatment of slaughterhouse wastewater in an expanded granular sludge bed (EGSB) reactor, Water Sci. Technol., 40(8), 99-106(1999).

39. E. Razo-Flores, P. Smulders, F. Prenafeta-Boldú, G. Lettinga, J. A. Field, Treatment of anthranilic acid in ananaerobic expanded granular sludge bed reactor at low concentration, Water Sci. Technol., 40(8), 187-194(1999).

40. M. T. Kato, S. Rebac, G. Lettinga, Anaerobic treatment of low- strength brewery wastewater in expanded granular sludge bed reactor, Appl. Biochem. Biotechnol., 76(1), 15-32(1999).

41. S. Rebac, J. B. Van Lier, P. Lens, A. J. M. Stams, F. Dekkers, K. Th. M. Swinkels, G. Lettinga, Paychrophilic anaerobic treatment of low strength wastewater, Water Sci. Technol., 39(5), 203-210(1999).

42. L. H. A. Habets, Introduction of the IC Reactors in the Paper Industry, Technical Report, Paques B. V., Netherlands, pp. 7(1999).

43. L. W. Deng, P. Zheng, Z. A. Chen, Anaerobic digestion and post-treatment of swine wastewater using IC-SBR process with bypass of raw wastewater, Process Biochem., 41(4), 965-969(2006).

44. F. Xu, H.-F. Miao, Z.-X. Huang, H.-Y. Ren, M.-X. Zhao, W.-Q. Ruan, Performance and dynamic characteristics of microbial communities in an internal circulation reactor for treating brewery wastewater, Environ. Technol., 34(20), 2881-2888(2013).

45. Y. Arcand, S. R. Guiot, M. Desrochers, C. Chavarie, Impact of the reactor hydrodynamics and organic loading on the size and activity of anaerobic granules, Chem. Eng. J. Biochem. Eng. J., 56(1), B23-B35(1994).

46. L. H. Pol, G. Lettinga, New technologies for anaerobic wastewater treatment, Water Sci. Technol., 18(12), 41-53(1986).

47. C. Nicolella, M. C. M. van Loosdrecht, J. J. Heijnen, Wastewater treatment with particulate biofilm reactors, J. Biotechnol., 80(1), 1-33(2000).

48. Y. Liu, Y. He, Y. Li, H. Tan, The application of suspended granular sludge technology in the design of high-rate anaerobic reactors, China Biogas, 23(2), 3-5(2005).

49. J. H. F. Pereboom, T. L. F. M. Vereijken, Methanogenic granule development in full scale internal circulation reactors, Water Sci. Technol., 30(8), 9-21(1994).

50. K. Guo, Y. Shang, B. Gao, X. Xu, S. Lu, Q. Qi, Study on the treatment of soybean protein wastewater by a pilot-scale IC-A/O coupling reactor, Chem. Eng. J., 343, 189-197(2018).

51. L. H. A. Habets, A. J. H. H. Engelaar, N. Groeneveld, Anaerobic treatment of inuline effluent in an internal circulation reactor, Water Sci. Technol., 35(10), 189-197(1997).

52. P. Cui, X. Zhou, Y. Zhang, The feasibility study of cotton pulp wastewater treatment with IC anaerobic reactor, Procedia Environ. Sci., 11(Part B), 686-692(2011).

53. J. D. Muñoz Sierra, M. J. Oosterkamp, W. Wang, H. Spanjers, J. B. van Lier, Comparative performance of upflow anaerobic sludge blanket reactor and anaerobic membrane bioreactor treating phenolic wastewater: overcoming high salinity, Chem. Eng. J., 366, 480-490(2019).

54. A. Foglia, C. Akyol, N. Frison, E. Katsou, A. L. Eusebi, F. Fatone, Long-term operation of a pilot-scale anaerobic membrane bioreactor (AnMBR) treating high salinity low loaded municipal wastewater in real environment, Sep. Purif. Technol., 236, 116279(2020).

55. W. Wang, B. Wu, S. Pan, K. Yang, Z. Hu, S. Yuan, Performance robustness of the UASB reactors treating saline phenolic wastewater and analysis of microbial community structure, J. Hazard. Mater., 331, 21-27(2017).

56. M. J. Lujan-Facundo, J. Fernandez-Navarro, J. L. Alonso-Molina, I. Amoros-Munoz, Y. Moreno, J. A. Mendoza-Roca, L. Pastor-Alcaniz, The role of salinity on the changes of the biomass characteristics and on the performance of an OMBR treating tannery wastewater, Water Res., 142, 129-137(2018).

57. X. Tan, I. Acquah, H. Liu, W. Li, S. Tan, A critical review on saline wastewater treatment by membrane bioreactor (MBR) from a microbial perspective, Chemosphere, 220, 1150-1162(2019).

58. R.-C. Jin, C. Ma, Q. Mahmood, G.-F. Yang, P. Zheng, Anammox in a UASB reactor treating saline wastewater, Process Saf. Environ. Prot., 89(5), 342-348(2011).

59. J. Lu, X. Yan, Y. Ma, C. Tian, J. Ding, Impact of salinity on treatment of saline wastewater by sequencing batch biofilm reactor process, J. Cent. South Univ., 21(5), 
1989-1994(2014).

60. J. Li, C. Jiang, W. Shi, F. Song, D. He, H. Miao, T. Wang, J. Deng, W. Ruan, Polytetrafluoroethylene (PTFE) hollow fiber AnMBR performance in the treatment of organic wastewater with varying salinity and membrane cleaning behavior, Bioresour. Technol., 267, 363-370(2018).

61. X. Shi, O. Lefebvre, K. K. Ng, H. Y. Ng, Sequential anaerobic - aerobic treatment of pharmaceutical wastewater with high salinity, Bioresour. Technol., 153, 79-86(2014).

62. F. Sadeghi, M. R. Mehrnia, R. Nabizadeh, M. H. Sarrafzadeh, Treatment of synthetic olefin plant wastewater at various salt concentrations in a membrane bioreactor, CLEAN-Soil Air Water, 40(4), 416-421(2012).

63. E. E. Rios-Del Toro, N. E. López-Lozano, F. J. Cervantes, Up-flow anaerobic sediment trapped (UAST) reactor as a new configuration for the enrichment of anammox bacteria from marine sediments, Bioresour. Technol., 238, 528-533 (2017).

64. N. Gharsallah, L. Khannous, N. Souissi, M. Nasri, Biological treatment of saline wastewaters from marine-products processing factories by a fixed-bed reactor, J. Chem. Technol. Biotechnol., 77(8), 865-870(2002).

65. C. Cortés-Lorenzo, M. Rodríguez-Díaz, C. López-Lopez, M. Sánchez-Peinado, B. Rodelas, J. González-López, Effect of salinity on enzymatic activities in a submerged fixed bed biofilm reactor for municipal sewage treatment, Bioresour. Technol., 121, 312-319(2012).

66. K. K. Ng, X. Shi, M. K. Y. Tang, H. Y. Ng, A novel application of anaerobic bio-entrapped membrane reactor for the treatment of chemical synthesis-based pharmaceutical wastewater, Sep. Purif. Technol., 132, 634-643(2014).

67. K. K. Ng, X. Shi, S. L. Ong, C.-F. Lin, H. Y. Ng, An innovative of aerobic bio-entrapped salt marsh sediment membrane reactor for the treatment of high-saline pharmaceutical wastewater, Chem. Eng. J., 295, 317-325(2016).

68. W. Song, L. Y. Lee, H. You, X. Shi, H. Y. Ng, Microbial community succession and its correlation with reactor performance in a sponge membrane bioreactor coupled with fiber-bundle anoxic bio-filter for treating saline mariculture wastewater, Bioresour. Technol., 295, 122284(2020).

69. J. Wen, H. Dong, G. Zeng, Application of zeolite in removing salinity/sodicity from wastewater: a review of mechanisms, challenges and opportunities, J. Cleaner Prod., 197(Part1), 1435-1446(2018).

70. S. Tan, C. Cui, Y. Hou, X. Chen, A. Xu, W. Li, H. You, Cultivation of activated sludge using sea mud as seed to treat industrial phenolic wastewater with high salinity, Mar. Pollut. Bull., 114(2), 867-870(2017).

71. J.-L. Huang, H.-H. Wang, F. Alam, Y.-W. Cui, Granulation of halophilic sludge inoculated with estuarine sediments for saline wastewater treatment, Sci. Total Environ., 682, 532-540(2019).

72. M. Ali, A. Elreedy, M. G. Ibrahim, M. Fujii, A. Tawfik, Hydrogen and methane bio-production and microbial community dynamics in a multi-phase anaerobic reactor treating saline industrial wastewater, Energy Convers. Manage., 186, 1-14(2019).

73. M. Hou, W. Li, H. Li, C. Li, X. Wu, Y. Liu, Performance and bacterial characteristics of aerobic granular sludge in response to alternating salinity, Int. Biodeterior. Biodegrad., 142, 211-217(2019)

74. J. K. Jiang, J. Wu, J. Zhang, S. Poncin, H. Z. Li, Multiscale hydrodynamic investigation to intensify the biogas production in upflow anaerobic reactors, Bioresour. Technol., 155, $1-7(2014)$

\section{Abbreviations}

COD : Chemical Oxygen Demand
SS : Suspended Solids
BOD : Biochemical Oxygen Demand
B/C : BOD/COD
SRB : Sulfate-Reducing Bacteria
MPB : Methanogens
UASB : Upflow Anaerobic Sludge Bed
EGSB : Expanded Granular Sludge Bed
IC : Internal Circulation
OLR : Organic Loading Rate

\section{Authors}

\section{Qinfang Lu}

School of Chemistry and Environment, Jiujiang University, Jiujiang, China, Department of Environmental Engineering, Kunsan National University, Gunsan, South Korea, Ph.D. Candidate, ORCID (1) 0000-0002-8099-8709

\section{Byung-gon Jeong}

Department of Environmental Engineering, Kunsan National University, Gunsan, South Korea, Professor, ORCiD [D 0000-00031327-4089

\section{Ping Yan}

School of Chemistry and Environment, Jiujiang University, Jiujiang, China, Dean

\section{Sohee Kim}

Department of Environmental Engineering, Kunsan National University, Gunsan, South Korea, Assitant

\section{Shirong Lai}

Science Environmental Protection Technology Thain Co. Ltd., Jiujiang, China, Senior Engineer

\section{Jiancheng Liu}

Lishan Environmental Protection Technology Co. Ltd. COFCO group, Jiujiang, China, General Manager 